\title{
Preparation of Rice Hull Activated Carbon for the Removal of Selected Pharmaceutical Waste Compounds in Hospital Effluent
}

\author{
Mukoko $\mathrm{T}^{1^{*}}$, Mupa $\mathrm{M}^{1^{*}}$, Guyo $\mathrm{U}^{2}$ and Dziike $\mathrm{F}^{3}$ \\ ${ }^{1}$ Department of Chemistry, Bindura University of Science Education, P. Bag 1020, Bindura, Zimbabwe \\ ${ }^{2}$ Department of Chemical Technology, Midlands State University, P Bag 9055, Gweru, Zimbabwe \\ ${ }^{3}$ School of Chemistry, University of Witwatersrand, Johannesburg, 2050, South Africa
}

\begin{abstract}
The adsorbent (activated carbon) was prepared from rice hull obtained from communal farmers in Mutoko North (Zimbabwe) by chemical activation using phosphoric acid and was used in the adsorption of aspirin, paracetamol and ibuprofen from hospital effluent. Characterization of the rice hull activated carbon was carried out using the following methods: SEM, XRD, FT- IR. Physical properties such as iodine number, porosity, ash content, moisture content and volatile matter content were also determined. lodine number was found to be $815.0 \pm 2.52 \mathrm{mg} / \mathrm{g}$. FT-IR analysis showed the presence of various functional groups such as $\mathrm{C}=\mathrm{O}, \mathrm{C}=\mathrm{C},-\mathrm{OH}$, and $\mathrm{C}-\mathrm{H}$ on the surface of the adsorbent whereas SEM micrograph showed that the external surface of the rice hull activated carbon is full of regular cavities. XRD pattern showed broad peaks indicating that rice hull activated carbon produced has amorphous structure.

The effect of adsorbent dose, contact time, initial concentration and $\mathrm{pH}$ was studied. Adsorption of aspirin fits the Freundlich isotherm, whereas ibuprofen and paracetamol fit the Langmuir isotherm. Kinetic studies showed that adsorption of ibuprofen, aspirin and paracetamol obey pseudo-second order kinetics.

Aspirin, paracetamol and ibuprofen were detected in two hospital wastewaters at the concentrations of $0.117 \pm$ $0.0058 \mathrm{mg} / \mathrm{L}, 0.100 \mathrm{mg} / \mathrm{L}$ and $0.010 \pm 0.0006 \mathrm{mg} / \mathrm{L}$ respectively. The studies showed that pharmaceutical compounds studied can be removed from wastewater using rice hull derived activated carbon.
\end{abstract}

Keywords: Aspirin; Emerging contaminants; Freundlich isotherm; Ibuprofen; Langmuir isotherm; Pharmaceuticals; Paracetamol

\section{Introduction}

Human and veterinary pharmaceutical compounds are a source of increasing environmental pollution because the compounds are used in large quantities and the physical and chemical properties of the compounds make them likely to be transported into hydrologic system [1].

Pharmaceuticals are synthetic or natural chemicals that can be found in prescription medicines, over-the-counter therapeutic drugs and veterinary drugs which contain active ingredients that have been designed to have pharmacological effects and confer significant benefits to society. They include painkillers, birth control pills, tranquilizers and anti-depressants [2] among many others.

Waste from pharmaceuticals fall in the category of emerging toxicants and pollutants. These pollutants are currently undergoing a regularization process although the directives and legal frameworks are not set-up yet [3].

The presence of pharmaceuticals at very low concentrations has raised concern among stakeholders, such as environment protection agencies, water authorities and the public in general, regarding the potential risks to human health from exposure to these chemicals via drinking water [2].

Pharmaceuticals find their way into the environment via human and animal excreta from disposal into the sewage system [4]. Their presence in water can also be attributed to pharmaceutical industry waste, hospital waste and therapeutic drugs [5]. They are not only released into the environment after use. Some are disposed during manufacture or as unused or expired drugs [6].

The impact on the environment and public health arises not only from wastewater effluents discharged in aquatic media [7], but also from sludge application in agriculture, since they can desorb and contaminate the groundwater [8]

Removal of pharmaceuticals from water by adsorption is one of the most promising techniques because of its convenience. Several adsorbents have been used to date. These include soils, clays, hydrous oxides and silica. Few studies have focused on removal of pharmaceuticals using activated carbon from agricultural wastes [9] Several agricultural by-products have been found to be suitable precursors for the production of activated carbon. The biomass obtained from these materials is cheaper, renewable, and abundantly available and have high carbon and low ash contents [10].

Aquatic organisms are vulnerable to pharmaceuticals. This is because of the high solubility of most pharmaceutical drugs. Estrogen from birth control pills eventually enters water sources. Increasing levels of estrogen in the environment, via pharmaceuticals for the purposes such as menopause symptom relief and birth control pills, could be causing adverse effects on humans, such as reduced male sperm counts and sperm motility and young ages of puberty in girls [11].

Pharmaceutical estrogens are responsible for a number of disorders

${ }^{*}$ Corresponding author: Mukoko T, Department of Chemistry, Bindura University of Science Education, P. Bag 1020, Bindura, Zimbabwe, Tel: +263 27163 722; E-mail: tichmukokogundani@hotmail.com

Received June 29, 2015; Accepted July 29, 2015; Published July 31, 2015

Citation: Mukoko T, Mupa M, Guyo U, Dziike F (2015) Preparation of Rice Hul Activated Carbon for the Removal of Selected Pharmaceutical Waste Compounds in Hospital Effluent. J Environ Anal Toxicol S7: 008. doi:10.4172/2161-0525.S7008

Copyright: ( 2015 Mukoko T, et al. This is an open-access article distributed under the terms of the Creative Commons Attribution License, which permits unrestricted use, distribution, and reproduction in any medium, provided the original author and source are credited. 
in fish. Male fish exposed to estrogens produce vitellogenin, a protein which is synthesized by females during oocyte maturation and earlystage eggs in their testes [12].

Pharmaceutical xenoestrogens are known to disrupt reproduction process because they act as "false messengers". Decrease in the number of sperms, testicular carcinoma and abnormal sperm shapes are some of the reproductive disorders commonly found in men [13].

Activated carbon is made from a number of waste materials such as coffee residues, fruit seeds and shells, wood, rice hulls [14], bagasse pith, palm pith, corn cob, bamboo and rubber seed coat [15].

Activated carbon is mainly used as an adsorbent as well as a catalyst support. These uses can be attributed to its unique characteristics such as high surface area, surface acid groups and micro and mesoporosity $[14,16]$. Activated carbons are made up of small hydrophobic graphite layers with disordered, irregular and heterogeneous surfaces bearing hydrophilic functional groups [17].

Langmuir and Freundlich isotherms are the commonly used isotherms used to describe adsorption. Equation for the Langmuir adsorption isotherm is used in the estimation of the maximum adsorption capacity $\left(\mathrm{q}_{\max }\right) \cdot \mathrm{q}_{\max }$ is the maximum quantity of adsorbate adsorbed per gram of activated carbon. The equation is represented as:

$$
\frac{C_{e}}{q_{e}}=\frac{1}{q_{m} b}+\frac{C_{e}}{q_{m}}
$$

where $q_{m}$ is the monolayer adsorption capacity $(\mathrm{mg} / \mathrm{g})$, b is the Langmuir constant $(\mathrm{L} / \mathrm{mg}), C_{e}$ is the equilibrium constant $(\mathrm{mg} / \mathrm{L})$ and $q_{e}$ is the amount adsorbed on adsorbent at equilibrium $(\mathrm{mg} / \mathrm{L})$ [17].

Freundlich isotherm is an empirical equation suited for nonideal systems with highly heterogeneous surfaces [15]. It gives good interpretation of data over a restricted concentration range. The equation is represented as:

$$
\log q_{e}=\log K_{F}+\left(\frac{1}{n}\right) \log C_{e}
$$

Where $K_{F}$ is the capacity of adsorption $(\mathrm{L} / \mathrm{mg})$ and $n$ is the intensity of adsorption.

Evaluation of adsorption kinetics is carried out using pseudo-first - order, pseudo - second order and intraparticle diffusion models [18]. Lagergren pseudo-first order is expressed as:

$$
\log \left(q_{e}-q_{t}\right)=\log q_{e}-\left(\frac{K_{1}}{2.303}\right) t
$$

where $q_{e}$ and $q_{t} \mathrm{mg} / \mathrm{g}$ ) are the amounts of adsorbate at equilibrium and time $t$ min) respectively, and $K_{1}\left(\mathrm{~min}^{-1}\right)$ is the rate constant for pseudo-first-order adsorption. The values of $\mathrm{K}_{1}$ and $q_{e}$ at different concentrations can be determined from the slope and intercept when $\log \left(q_{e}-q_{t}\right)$ is plotted against $t$. The equation for the pseudo-secondorder is expressed as:

$$
\frac{t}{q_{t}}=\left(1 /\left(K_{2} q_{e}^{2}\right)\right)+\left(\frac{1}{q_{e}}\right) t
$$

where $K_{2}(\mathrm{~g} / \mathrm{mg} \mathrm{min})$ is the pseudo-second-order rate constant. The values of $q_{e}$ and $K_{2}$ can be determined from the slope and intercept of the plot $t / q_{t}$ against $t$.

Intraparticle diffusion model is shown in equation (5)

$$
q_{t}=k_{i d}+t^{\left(\frac{1}{2}\right)}+C_{i}
$$

Where $k_{i d}\left(\mathrm{mg} \mathrm{g}^{-1} \min ^{-1(1 / 2)}\right.$ is the measure of diffusion coefficient and $C_{i}\left(\mathrm{mg} \mathrm{g}^{-1}\right)$ is the intraparticle diffusion constant which is directly proportional to the boundary layer thickness. Plot of $q_{t}$ vs. $t^{(1 / 2)}$ gives the rate constant, $K_{i d}$ from the slope and $C_{i}$ from the intercept.

A number of analytical techniques for the determination of pharmaceuticals and their metabolites are currently being used. These include UV-Vis spectrophotometry, chromatographic and electrophoretic techniques.

\section{Methods}

\section{Materials and reagents}

Rice (Oryza glaberrima) hulls were harvested from Charehwa area of Mutoko North in Mashonaland East, Zimbabwe. All reagents were of reagent grade unless otherwise specified. Aspirin, paracetamol and ibuprofen standards were purchased from Merck (Pvt) Ltd, South Africa and were used without further purification. Hydrochloric acid and sodium hydroxide were purchased from Skylabs (Pvt) Ltd, South Africa and were used in the preparation of stock solutions. Ammonium chloride, methylene chloride and ammonium sulphate were obtained from Minema (Pvt) Ltd, Saarchem (Pvt) Ltd and ACE (Pvt) Ltd respectively in South Africa and were used in liquid-liquid extraction experiments. Sodium thiosulphate and iodine were purchased from Skylabs (Pvt) Ltd, South Africa and Park Scientific Limited, UK and were used in the determination of iodine number of the activated carbon whereas double distilled water was used in the preparation of aqueous solutions.

\section{Sampling and sample preparation}

The rice hulls were washed with distilled water to remove impurities and then dried at $110^{\circ} \mathrm{C}$ for 8 hours. This was followed by grinding and sieving to a particle size of 1-2 $\mathrm{mm}$.

\section{Preparation of activated carbon}

Procedure was adapted from [19] with slight modifications. The rice hull ground particles were impregnated with phosphoric acid (85\%) with a density of $1.71 \mathrm{~g} \mathrm{~cm}^{-3}$ and the mixture kept in an oven for 24 hours at $100^{\circ} \mathrm{C}$. The mixture was then carbonized and activated in a programmable muffle furnace for 30 minutes at $500^{\circ} \mathrm{C}$. The chemically activated product was cooled to room temperature and then washed with hot distilled water until the $\mathrm{pH}$ of the filtrate was between 6.5 and 7 . The activated carbon was dried overnight at $110^{\circ} \mathrm{C}$ and then characterized using FTIR, SEM and XRD.

\section{Characterization of rice hull activated carbon}

Surface morphology of prepared activated carbon was analyzed using scanning electron microscopy (SEM, Quanta FEG 250) at 5.00 KV. Everhart - Thornley detector (ETD) was used as a detector and a working distance (WD) of $10.1 \mathrm{~mm}$ was used for high resolution imaging. The activated carbon sample was ground to a powder and mounted on the standard specimen stubs using adhesive tape and then coated with gold layer to prevent the sample from charging. Functional groups were determined using Fourier Transform Infrared Spectrophotometer (FTIR, WQF-520) manufactured by Analytical Technologies (India) operating between 600 and $3600 \mathrm{~cm}^{-1}$ using $\mathrm{KBr}$ pellet method. A $0.02 \mathrm{~g}$ sample of rice hull activated carbon was powdered and then mixed with $0.3 \mathrm{~g}$ of anhydrous $\mathrm{KBr}$. Pellets were obtained by pressing the mixture in a vacuum. Air spectrum was subtracted from the sample spectra. The degree of crystallinity or amorphous nature of activated carbon was determined using a Bruker D8 Discover X-ray diffractometer with nickel filtered $\mathrm{Cu}-\mathrm{Ka}$ radiation 
source. Rice hull activated carbon was dried and finely ground and tested at $40 \mathrm{kV}$ and $40 \mathrm{~mA}$, using argon filled proportional counter detector. A scan mode $2 \theta=5-90^{\circ}$ was used.

\section{Physical properties of rice hull and activated carbon}

Moisture content determination: The method was adapted from [20] with slight modifications. Moisture content was determined by oven drying $5 \mathrm{~g}$ of rice hull at $110^{\circ} \mathrm{C}$ until a constant weight was obtained after 24 hours. The moisture content was calculated using equation (6).

$$
\text { Moisture content }=\frac{\text { Initial mass of hull }- \text { Mass of dried hull }}{\text { Initial mass of hull }} \times 100
$$

Ash content determination: Method is based on procedure by [21] with slight modifications. Rice hull and activated carbon samples $\left(10.0 \mathrm{~g}\right.$ each) were oven heated separately at $80^{\circ} \mathrm{C}$ for 24 hours. Dried samples were then heated in a muffle furnace at $600^{\circ} \mathrm{C}$ for 3 hours. After heating, the crucible and contents were cooled in a desiccator followed by weighing. The ash content was calculated using equation (7).

$$
\frac{(\text { Remaining solids weight })}{(\text { original material weight })} \times 100 \frac{(\text { Remaining solids weight })}{(\text { original material weight })} \times 100
$$

Loss on ignition (LOI) of rice hull: The method was adapted from [22]. A $10.0 \mathrm{~g}$ sample was oven-heated at $110^{\circ} \mathrm{C}$ for 6 hours to remove residual moisture. The dried sample was put in a silica crucible and heated in a muffle furnace at $550^{\circ} \mathrm{C}$ for 1 hour. The crucible was cooled in a desiccator and volatile solids or loss on ignition determined as the percentage loss using equation (8).

$$
\text { LOI }=\frac{(\text { Initial mass }- \text { Final mass })}{\text { Initial mass }} \times 100
$$

Bulk density: The method was adapted from [23]. A glass cylinder $\left(25 \mathrm{~cm}^{3}\right)$ was filled with finely ground activated carbon powder and dried overnight in an oven at $80^{\circ} \mathrm{C}$. The cylinder was cooled and then tapped for 1-2 minutes for the carbon to compact and the bulk density calculated using equation (9).

$$
\text { Density }=\frac{\text { Weight of dry material }(\mathrm{g})}{\text { Volume of packed drymaterial }\left(\mathrm{cm}^{3}\right)} \times 100
$$

The experiments were carried out in triplicate and the average value found.

Iodine number: The method was adapted from Birbas et al. [24]. Activated carbon of mass $0.1 \mathrm{~g}$ was put into the conical flask containing $25 \mathrm{~cm}^{3}$ of iodine solution. The sample was mixed with iodine solution for about a minute by swirling. The activated carbon - iodine mixture was then filtered and $10 \mathrm{~cm}^{3}$ of the filtered solution was put into another flask using volumetric pipette. The filtered solution was then titrated with $0.04 \mathrm{~N}$ sodium thiosulphate solutions until it became clear.

\section{Stock and standard solutions}

Preparation of stock and calibration standard solutions: Stock solution of paracetamol was prepared by dissolving $0.1 \mathrm{~g}$ paracetamol (A.R) in $100 \mathrm{~cm}^{3}$ methanol in $100 \mathrm{~cm}^{3}$ volumetric flask. The contents were mixed well and kept aside for 15 minutes at room temperature. Calibration standards were prepared by pipetting 2.5, 5, 7.5 and $10 \mathrm{~cm}^{3}$ of stock solution and diluting to the mark using methanol in $100 \mathrm{~cm}^{3}$ volumetric flasks to form 25, 50, 75 and $100 \mathrm{mg} / \mathrm{L}$ standard solutions.

For aspirin stock solutions, $0.1 \mathrm{~g}$ of standard aspirin were dissolved in $100 \mathrm{~cm}^{3}$ of methanol in $100 \mathrm{~cm}^{3}$ volumetric flask to give $1000 \mathrm{mg} / \mathrm{L}$.
The contents were thoroughly mixed and kept aside for 15 minutes. Calibration standards of 50,100, 150 and $200 \mathrm{mg} / \mathrm{L}$ were prepared by pipetting 5,10,15 and $20 \mathrm{~cm}^{3}$ of stock solution into $100 \mathrm{ml}$ volumetric flask and then topped to mark using methanol. Methanol was used as blank for UV-Vis spectrophotometric analysis.

Ibuprofen stock solution was prepared by dissolving $0.1 \mathrm{~g}$ of ibuprofen (A.R) in methanol in $100 \mathrm{~cm}^{3}$ volumetric flask. Calibration standards were prepared by pipetting $5,10,15$ and $20 \mathrm{~cm}^{3}$ of stock solution into $100 \mathrm{~cm}^{3}$ volumetric flasks. The contents were then topped to the mark using methanol to form 50,100, 150 and $200 \mathrm{mg} / \mathrm{L}$ standard solutions. Methanol was used as a blank.

Derivatization of aspirin and paracetamol: Derivatization of aspirin, paracetamol was carried out to eliminate interferences, that is, most solvents and other extraneous matter that are common in the $200-330 \mathrm{~nm}$ region. Thus, the main challenge of the research was to carry out derivative formation which shifted the absorption maximum to the colorimetric and mid - spectrum range which is $380-800 \mathrm{~nm}$. Colorimetric methods selectively transform a drug so that its spectrum is shifted away from the interference caused by other drugs or to the visible region thereby conferring a degree of specificity.

Aspirin was hydrolyzed in basic medium $(0.1 \mathrm{M} \mathrm{NaOH})$ to give salicylate dianion as shown below (Scheme 1).

The resulting dianion was derivatized with $\mathrm{Fe}$ (III) to give a violet colored tetraaquosalicylatroiron (III) complex.

Derivatization of paracetamol involved reaction of paracetamol and iron (III) and subsequent reaction with ferricyanide in acid to give a Prussian blue solution. The mechanism involves reduction of iron (III) by paracetamol to iron (II), which subsequently reacts with ferricyanide, in acidic medium to give Prussian blue product [25] (Scheme 2).

A Prussian blue color formed is due to the reaction of potassium ferricyanide with iron (II). The intensity of the color is proportional to the concentration of paracetamol

$$
\mathrm{K}_{3}\left[\mathrm{Fe}(\mathrm{CN})_{6}\right]+\mathrm{Fe}^{2+} \rightarrow\left[\mathrm{Fe}_{4}\left[\mathrm{Fe}(\mathrm{CN})_{6}\right]_{3}\right]
$$

Preparation of derivatized aspirin and paracetamol solutions: Paracetamol solution was prepared by dissolving $0.1 \mathrm{~g}$ paracetamol (A.R) in $20 \mathrm{~cm}^{3}$ methanol in $100 \mathrm{~cm}^{3}$ volumetric flasks. This was followed by addition of $1.0 \mathrm{~cm}^{3}$ of $0.1 \%(\mathrm{w} / \mathrm{v})$ ferric chloride, $1.0 \mathrm{~cm}^{3}$ of $0.065 \%(\mathrm{w} / \mathrm{v})$ potassium ferricyanide and $1 \mathrm{~cm}^{3}$ of $2 \mathrm{M}$ acetic acid each to the flask. The contents were mixed well and diluted to mark using 1 $\mathrm{N} \mathrm{HCl}$ to give $1000 \mathrm{mg} / \mathrm{L}$ solution. A Prussian blue color was formed.

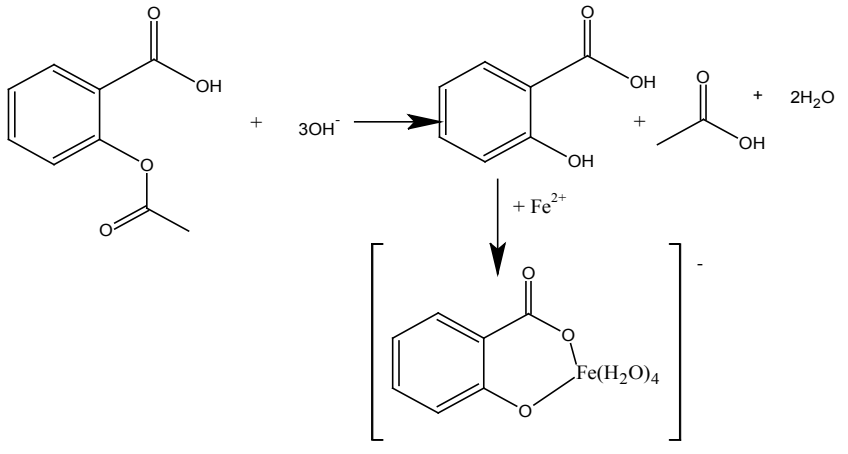

Scheme 1: Derivatization of aspirin. 
<smiles>CC(=O)Nc1ccc(O)c([18OH])c1</smiles>

paracetamol

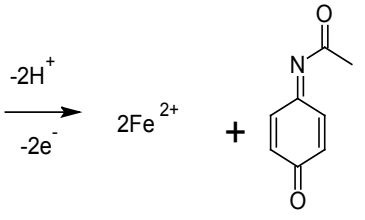

$\mathrm{N}$-acetyl-p-quinine imine
Scheme 2: Derivatization of paracetamol.

Aspirin solutions were prepared by dissolving $0.1 \mathrm{~g}$ aspirin (A.R) in $20 \mathrm{~cm}^{3}$ of distilled water. Exactly $10 \mathrm{~cm}^{3}$ of $1.0 \mathrm{M} \mathrm{NaOH}$ were added and the contents heated to boiling. After cooling to room temperature, the contents were diluted to mark using $0.025 \mathrm{M} \mathrm{FeCl}_{3}$ to give 1000 $\mathrm{mg} / \mathrm{L}$ solution. A purple solution was formed.

\section{Selection of analytical wavelengths for pharmaceutical drugs}

Underivatized standard solutions (200 $\mathrm{mg} / \mathrm{L})$ for ibuprofen, aspirin and paracetamol were separately prepared by diluting $20 \mathrm{ml}$ of stock solution of each drug in $100 \mathrm{~cm}^{3}$ methanol. Each solution was scanned in the wavelength range of $200-400 \mathrm{~nm}$ using UV-Vis spectrophotometer so that the maximum absorption wavelength $\left(\lambda_{\max }\right)$ for each drug was determined. Derivatized standard solution (200 $\mathrm{mg} / \mathrm{L}$ ) of aspirin was scanned in the wavelength range of 350 to $600 \mathrm{~nm}$ and that of paracetamol was scanned between 550 and $800 \mathrm{~nm}$.

\section{Batch equilibrium studies}

Effect of contact time on adsorption: Aqueous solutions $\left(50 \mathrm{~cm}^{3}\right)$ of the drug solution at $25 \mathrm{mg} / \mathrm{L}$ (aspirin), $100 \mathrm{mg} / \mathrm{L}$ (paracetamol) and $50 \mathrm{mg} / \mathrm{L}$ (ibuprofen) were placed in conical flasks and $0.5 \mathrm{~g}$ of activated carbon added to each tube. The contents were shaken for a minute. The mixtures were centrifuged at $135 \mathrm{rpm}$ and the filtrates for aspirin and paracetamol derivatized. Aspirin filtrate was derivatized by adding $1 \mathrm{~cm}^{3}$ of $1.0 \mathrm{M} \mathrm{NaOH}$ and then heated to boiling. The contents were cooled to room temperature followed by addition of $3 \mathrm{~cm}^{3}$ of $0.025 \mathrm{M}$ $\mathrm{FeCl}_{3}$.

Paracetamol was derivatized by adding $1 \mathrm{~cm}^{3}$ of $0.1 \%(\mathrm{w} / \mathrm{v})$ ferric chloride, $1 \mathrm{~cm}^{3}$ of $0.065 \%(\mathrm{w} / \mathrm{v})$ potassium ferricyanide $(0.02$ $\mathrm{M})$ and $1 \mathrm{~cm}^{3}$ of $2 \mathrm{M}$ acetic acid each to the filtrate. Ibuprofen and derivatized aspirin and paracetamol filtrates were analyzed using UV Vis spectrophotometer.

Effect of adsorbent dose on adsorption: Aqueous solutions (50 $\mathrm{cm}^{3}$ ) of each drug solution at $50 \mathrm{mg} / \mathrm{L}$ were placed in four different conical flasks containing $0.5,1.0,2.0$ and $3.0 \mathrm{~g}$ of activated carbon. The contents were shaken for a minute. The mixtures were centrifuged at $135 \mathrm{rpm}$ and the filtrates for aspirin and paracetamol derivatized as indicated in section on derivatization. The filtrates were analyzed using $\mathrm{UV} / \mathrm{Vis}$ spectrophotometer.

Effect of pH on adsorption: Aqueous solutions $\left(50 \mathrm{~cm}^{3}\right)$ of the drug solution at $150 \mathrm{mg} / \mathrm{L}$ (aspirin), $50 \mathrm{mg} / \mathrm{L}$ (ibuprofen) and 100 $\mathrm{mg} / \mathrm{L}$ (paracetamol) are placed in conical flasks. The $\mathrm{pH}$ values of the solutions were adjusted to values shown in Table 1 using $0.1 \mathrm{M} \mathrm{HCl}$ or $0.1 \mathrm{M} \mathrm{NaOH}$ followed by addition of $2.0 \mathrm{~g}$ of activated carbon added to each tube. The contents were shaken for a minute. The mixtures were centrifuged at $135 \mathrm{rpm}$ and the filtrates for aspirin and paracetamol derivatized as indicated in section on derivatization. The filtrates were analyzed using UV/Vis spectrophotometer.
Effect of initial drug concentration: Aqueous solutions $\left(50 \mathrm{~cm}^{3}\right)$ of each drug at concentrations shown in Table 2 were placed in conical flasks containing $2.0 \mathrm{~g}$ of activated carbon. The contents were shaken for a minute. The mixtures were centrifuged at $135 \mathrm{rpm}$ and the filtrates for aspirin and paracetamol derivatized as indicated in effect of contact time on adsorption. The mixtures are centrifuged and filtered. The filtrate is analyzed using UV/Vis spectrophotometer.

Effect of co - adsorption on removal of aspirin, paracetamol and ibuprofen: Aqueous solutions $\left(60 \mathrm{~cm}^{3}\right)$ containing $20 \mathrm{~cm}^{3}$ of each drug was placed in conical flask. The $\mathrm{pH}$ was adjusted to the natural drug $\mathrm{pH}$ of 4 using $0.1 \mathrm{M} \mathrm{NaOH}$ and $0.1 \mathrm{M} \mathrm{HCl}$ and $2.0 \mathrm{~g}$ of activated carbon added. The contents were shaken for a minute. The mixtures were centrifuged at $135 \mathrm{rpm}$ and the filtrates divided into three separate sub-samples. The first sub-sample was used for the determination of aspirin and was derivatized as indicated in effect of contact time on adsorption. The second sub-sample was used for the determination of ibuprofen and the third one was derivatized as indicated in effect of contact time on adsorption for the determination of paracetamol. Analysis was carried out using UV/Vis spectrophotometer.

\section{Sample collection and preservation}

Three discrete samples of the effluent were collected in pyrex borosilicate glass containers from hospital septic tank. Formaldehyde

\begin{tabular}{|c|c|c|c|}
\hline Isotherm models & Aspirin & Ibuprofen & Paracetamol \\
\hline \multicolumn{4}{|l|}{ Langmuir } \\
\hline$q_{m}(m g / g)$ & 178.89 & 100 & 169.49 \\
\hline $\mathrm{b}(\mathrm{L} / \mathrm{mg})$ & 0.161 & 0.152 & 0.117 \\
\hline $\mathrm{R}_{\mathrm{L}}$ & 0.058 & 0.116 & 0.0787 \\
\hline $\mathrm{R}^{2}$ & 0.824 & 0.9995 & 0.9997 \\
\hline \multicolumn{4}{|l|}{ Freundlich } \\
\hline $\mathrm{K}_{\mathrm{F}}\left(\mathrm{mg} \mathrm{g}^{1-1 / n} \mathrm{~L}^{1 / \mathrm{n}} \mathrm{g}^{-1}\right)$ & 25.942 & 17.22 & 30.213 \\
\hline $\mathrm{n}$ & 1.842 & 1.894 & 2.270 \\
\hline $\mathrm{R}^{2}$ & 0.9942 & 0.9899 & 0.9811 \\
\hline$q_{e}(m g / g)$ & 46.989 & 25.074 & 16.827 \\
\hline
\end{tabular}

Table 1: Isotherm models constants and correlation coefficients for the adsorption of aspirin, ibuprofen and paracetamol onto rice hull-derived activated carbon.

\begin{tabular}{|c|c|c|c|}
\hline & Aspirin & Paracetamol & Ibuprofen \\
\hline \multicolumn{4}{|l|}{ Pseudo-first order } \\
\hline $\mathrm{K}_{1}(1 / \mathrm{min})$ & -1.458 & 0.009 & 0.468 \\
\hline $\mathrm{q}_{\mathrm{e}}(\mathrm{mg} / \mathrm{g})$ & 0.061 & 2.160 & 3.724 \\
\hline $\mathrm{R}^{2}$ & 0.686 & 0.655 & 0.786 \\
\hline \multicolumn{4}{|c|}{ Pseudo-second order } \\
\hline $\mathrm{K}_{2}(\mathrm{~g} / \mathrm{mg} \min )$ & 0.288 & $4.069 \times 10^{-4}$ & $9.338 \times 10^{-3}$ \\
\hline$q_{e}(m g / g)$ & 48.077 & 217.39 & 50.256 \\
\hline $\mathrm{R}^{2}$ & 0.9995 & 0.9973 & 1.000 \\
\hline \multicolumn{4}{|l|}{ Intraparticle diffusion } \\
\hline $\mathrm{K}_{\text {id }}\left(\mathrm{mg} \mathrm{g}^{-1} \mathrm{~min}^{1 / 1 / 1 / 2)}\right.$ & 0.732 & 9.056 & 0.282 \\
\hline$C_{i}\left(\mathrm{mg} \mathrm{g}^{-1}\right)$ & 38.63 & 107.27 & 46.12 \\
\hline $\mathrm{R}^{2}$ & 0.9256 & 0.9349 & 0.833 \\
\hline
\end{tabular}

Table 2: Kinetic parameters for the removal of aspirin, paracetamol and ibuprofen 
(1-3\%) was added to prevent changes in composition due to biodegradation. The samples were then stored in the dark at $4^{\circ} \mathrm{C}$ before analysis.

\section{Extraction of selected pharmaceuticals from hospital wastewater}

The method was adapted from [26]. Wastewater was filtered with Whatmann filter paper number 40 to remove suspended matter. To a sample of $20 \mathrm{~cm}^{3}$ in a separating funnel, $5 \mathrm{~cm}^{3}$ of $1.5 \mathrm{M}\left(\mathrm{NH}_{4}\right)_{2} \mathrm{SO}_{4}$, $1 \mathrm{~cm}^{3}$ of $3 \mathrm{M} \mathrm{HCl}$ and $20 \mathrm{~cm}^{3}$ of methylene chloride were added. The mixture was shaken vigorously for a minute. The mixture was allowed to stand until two phases separated. The organic layer which contained aspirin, ibuprofen and paracetamol was concentrated in rotor vapor and then collected. The sample $\mathrm{pH}$ was adjusted to natural drug $\mathrm{pH}$ of 4. The extract was divided into three separate portions for analysis of aspirin, ibuprofen and paracetamol. The first portion was used for the determination of ibuprofen. After determining the initial concentration of ibuprofen in sample, adsorption and filtration was carried out and the final concentration determined using UV/Vis spectrophotometer at $\lambda_{\max }=225 \mathrm{~nm}$.

The second portion was subdivided into two separate samples for determination of aspirin. One of the portions was derivatized as indicated in effect of contact time on adsorption and the initial drug concentration measured using the derivatized sample. Activated carbon $(2.0 \mathrm{~g})$ was suspended in underivatized sample. The mixture was shaken for a minute and then centrifuged at $135 \mathrm{rpm}$ for 90 minutes followed by filtration. The filtrate was derivatized and the final drug concentration determined using UV/Vis spectrophotometer at $\lambda_{\text {max }}=538 \mathrm{~nm}$.

The third portion was used for the determination of paracetamol. The extract was divided into two portions. One of the portions was derivatized as indicated in effect of contact time on adsorption and the initial drug concentration measured using the derivatized sample. Activated carbon $(2.0 \mathrm{~g})$ was suspended in underivatized sample. The mixture was shaken for a minute and then centrifuged at $135 \mathrm{rpm}$ for 135 minutes followed by filtration. The filtrate was derivatized and the final drug concentration was determined using UV/Vis spectrophotometer.

\section{Statistical analysis}

Experiments were carried out in triplicates and statistical tools such as mean, standard deviation and correlation coefficient $\left(\mathrm{R}^{2}\right)$ were used to assess experimental data. The Dixon's Q - test was used to test for the suspected outliers. Data from adsorption experiments was fitted to the Langmuir, Freundlich, pseudo-first order and pseudo secondorder models. Coefficient of determination $\left(\mathrm{R}^{2}\right)$ was used to determine best fit for each model.

\section{Results and Discussion}

\section{Characterization of rice hull derived activated carbon}

Surface functional groups identification using FT-IR: Surface functional group analysis was performed using Fourier Transform Infrared Spectrophotometer (FTIR, WQF-520) manufactured by Analytical Technologies (India) operating between 600 and $3600 \mathrm{~cm}^{-1}$ using $\mathrm{KBr}$ pellet method. Spectral bands were observed at 1390 - 1400, 1640 and $3425-3490 \mathrm{~cm}^{-1}$ as shown in Figure 1.

The broad band around $3425-3490 \mathrm{~cm}^{-1}$ can be attributed to the stretching vibration of the hydroxyl (v O-H) functional group [27] or maybe due to binding of the hydroxyl group with polymeric structure of rice hulls [28].

Spectral band around $1640 \mathrm{~cm}^{-1}$ corresponds to the stretching of the carbonyl $(v \mathrm{C}=\mathrm{O})$ groups that may be attributed to the hemicelluloses and lignin aromatic groups [29] or it can be due to stretching of unsaturated aliphatic $(v C=C)$ structures. Peak around $1390-1400 \mathrm{~cm}^{-1}$ can be attributed to aromatic $\mathrm{C}-\mathrm{H}$ and carboxyl-carbonate structures.

Surface morphology analysis: SEM was used to study the morphological features and surface characteristics of the rice hull derived activated carbon (adsorbent) used in the study for adsorption of aspirin, paracetamol and ibuprofen (Figure 2). SEM micrograph for the activated carbon showed that the adsorbent prepared from rice hull has a highly porous structure with regular mesopores [30]. The pores on the surface are clearly identifiable. This indicates that the external surfaces of the $\mathrm{H}_{3} \mathrm{PO}_{4}$ activated carbon have a lot of cavities which are suitable for adsorption to occur.

X-ray diffraction analysis (XRD) analysis: XRD pattern showed broad diffraction peak which is centered at $2 \theta=22^{\circ}$. This indicates that the activated carbon prepared from rice hull was predominantly amorphous as the existence of broad peaks indicates that the material is amorphous. The XRD pattern is similar to those obtained by [31] who studied the removal of dyes and heavy metals using rice hull activated carbon and [32] who prepared activated carbon prepared from paulownia sawdust (Figure 3).

Proximate analysis: Ash content was found to be $20.161 \pm 0.04 \%$. This represents various mineral substances that are not chemically combined with the carbon surface (Table 3). The mechanical strength and adsorptive capacity of activated carbon are both reduced by the presence of high ash content. High ash content is undesirable as it will affect development of the pore structure. As a way of reducing ash content in the activated carbon prepared in this research, the precursor (rice-hull) was acid $\left(\mathrm{H}_{3} \mathrm{PO}_{4}\right)$ treated before pyrolysis and activation processes. This resulted in the reduced ash content of $12.31 \pm 0.02 \%$ for activated carbon compared to the $20.161 \pm 0.04 \%$ of the precursor. The ash content of the rice hull is however closer to the $19.2 \%$ obtained in previous study and is within the $14-25 \%$ range reported.

The moisture content for Zimbabwean rice (Oryza glaberrima) hull was found to be $5.64 \pm 0.06 \%$. This value is within the $4.60-6.07 \%$ range reported in previous study [20] for Egyptian, Cuban and Chinese short grain rice but however higher than the $4.2 \%$ reported [22] for Indian rice hull. The differences can be attributed to the different collection and storage methods, varieties as well as the drying procedures where different temperatures have been used.

The bulk density of $513 \pm 1.51 \mathrm{~g} / \mathrm{cm}^{3}$ is lower than those reported [20] who obtained values ranging from $531.59 \mathrm{~kg} / \mathrm{m}^{3}$ for the short grain rice up to $580.54 \mathrm{~kg} / \mathrm{m}^{3}$ for the japonica rice husk. However, the average bulk density of rice hull activated carbon is within the required range of $200-750 \mathrm{~kg} / \mathrm{m}^{3}$ according to specification SAJH CH/PAC/001 (Rev.1.01/01.2005)

Iodine number is used in the determination of the adsorptive capacity of activated carbon. The iodine number of activated carbon was $815 \pm 2.52 \mathrm{mg} / \mathrm{g}$, which is within the recommended range of 600 to $1100 \mathrm{mg} / \mathrm{g}$. This indicates that the rice hull derived activated carbon has high adsorptive capacity and can be used in water treatment for the removal of organic compounds, pharmaceuticals included. The iodine value obtained indicates higher degree of activation. 


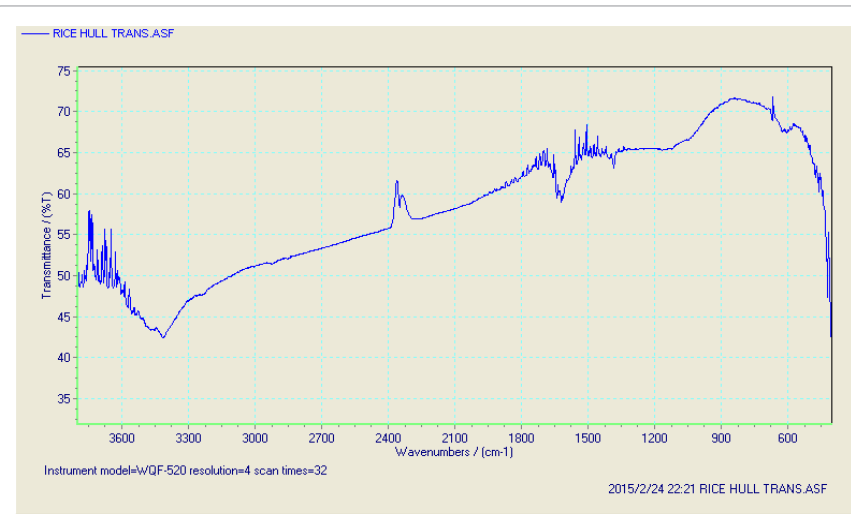

Figure 1: FT-IR spectrum of rice hull activated carbon prepared at $500^{\circ} \mathrm{C}$.

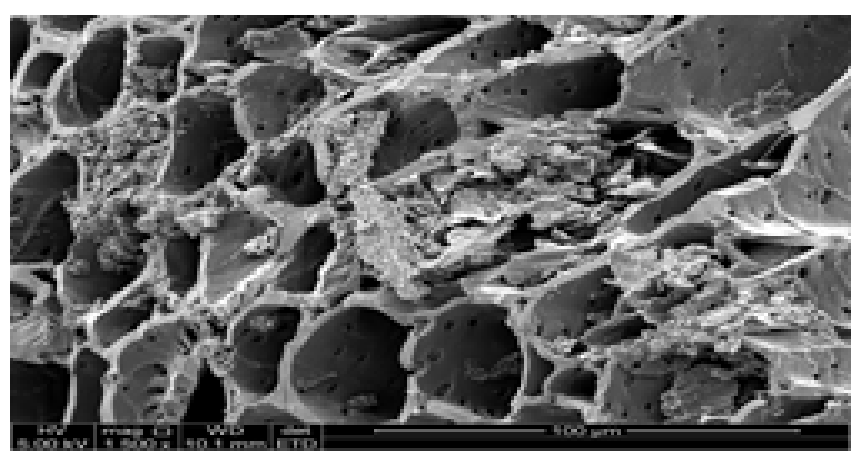

Figure 2: Surface morphology analysis of rice hull.

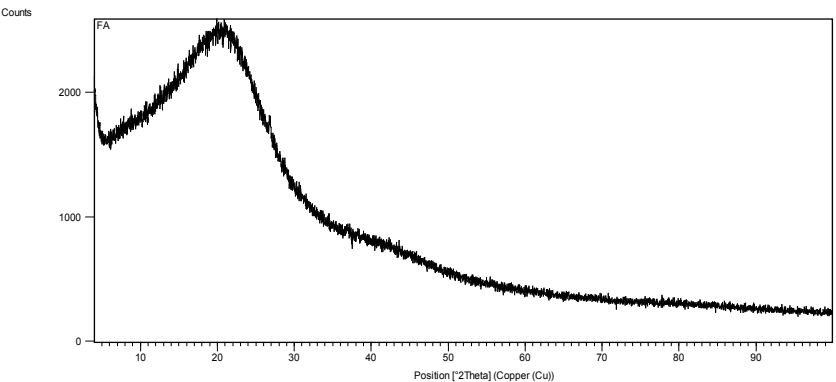

Figure 3: X-ray diffraction pattern of activated carbon produced at $500^{\circ} \mathrm{C}$.

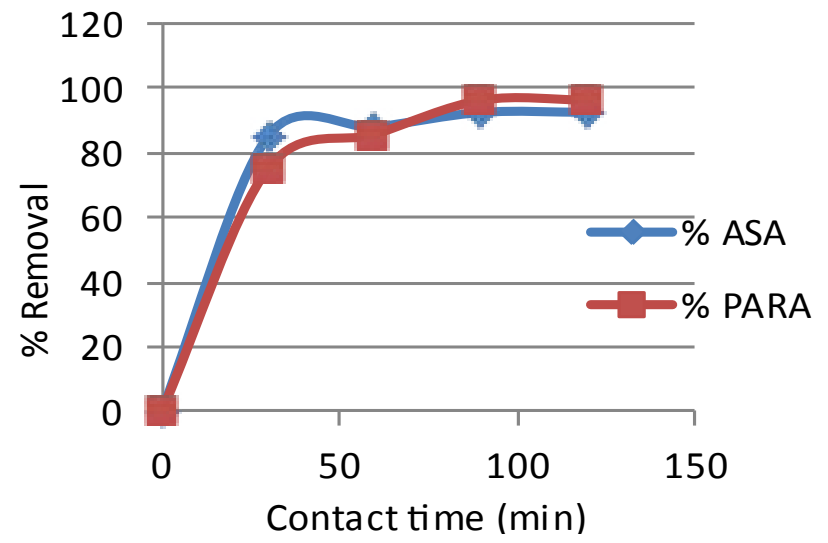

Figure 4: Effect of contact time on adsorption of aspirin and paracetamol.

\begin{tabular}{|c|c|c|}
\hline Property & Activated carbon & Rice hull \\
\hline Moisture content $(\%)$ & $4.680 \pm 0.02$ & $5.640 \pm 0.06$ \\
\hline Bulk density $\left(\mathrm{kg} / \mathrm{m}^{3}\right)$ & $513.0 \pm 1.51$ & - \\
\hline Ash content $(\%)$ & $12.31 \pm 0.02$ & $20.161 \pm 0.04$ \\
\hline lodine number $(\mathrm{mg} / \mathrm{g})$ & $815.0 \pm 2.52$ & - \\
\hline Volatile matter $(\%)$ & - & $55.517 \pm 0.01$ \\
\hline Carbon yield $(\%)$ & - & $36.057 \pm 0.04$ \\
\hline
\end{tabular}

Table 3: Physical properties of rice (Oryza glaberrima) hull and activated carbon.

Volatility is determined from weight loss. The decrease in weight at very high temperatures is due to devolatization of the rice hull. Devolatization is due to increase in pore development as well as creation of new pores, as a result of intensifying dehydration and elimination reactions. Volatile matter at $55.517 \pm 0.01 \%$ is lower than $62.0 \%$ obtained in previous study [22].

\section{Optimization of aspirin, paracetamol and ibuprofen adsorption parameters}

Rice hull supplied by communal farmers in Mutoko North was used to prepare an adsorbent that was used in the removal of ibuprofen, paracetamol and aspirin under different $\mathrm{pH}$, adsorbent doses, and initial drug concentrations and contact times. Agitation time used was $135 \mathrm{rpm}$ (Figures 4-9).

Effect of contact time on adsorption of aspirin, ibuprofen and paracetamol: Effect of contact time was studied to come with the shortest possible time when activated carbon adsorbs high concentration of the aspirin, paracetamol and ibuprofen. Figures 4 and 5 illustrate the effect of contact time on adsorption of aspirin, paracetamol ibuprofen and onto rice-hull derived activated carbon. The general trend observed is that there was increase in adsorption for all the drugs under study with increase in contact time until equilibrium is achieved.

Adsorption of aspirin increases with increase in contact time up to 90 minutes where it becomes constant. Adsorption rate initially increases but gradually decreases as adsorption sites become saturated. Removal rates of aspirin between 90 minutes and 120 minutes are almost constant and therefore, steady state approximation was assumed and quasi-equilibrium situation.

It can be seen from Figure 4 that there was rapid adsorption of aspirin during the first 30 minutes. The adsorption rate then decreases gradually until equilibrium is attained in about 90 minutes. Maximum adsorption was observed after 75 minutes, and quasi-equilibrium situation was accepted between 75 and 100 minutes.

Adsorption of ibuprofen was rapid during the first 45 minutes as high percentage adsorption of $95.425 \%$ was attained. The adsorption trend observed for ibuprofen is similar for all the drugs. Large number of vacant sites on activated carbon contributes to high adsorption during initial stages of contact period. At higher contact times, adsorption slows down due to repulsive forces between ibuprofen molecules on the solid and bulk phases [33]. The rate of increase in adsorption slowed down after 45 minutes and quasi-equilibrium situation was attained between 135 and 180 minutes.

The rapid increase in adsorption of all the drugs at shorter contact times can be attributed to a large number of vacant sites available for adsorption during the initial adsorption stage. The high removal rates within the initial stages were also caused by high concentration difference between the solid phase and bulk solution [34].

With time, the remaining adsorption sites become difficult to 
occupy. It can be noted that at higher contact times, aggregation of aspirin, paracetamol and ibuprofen molecules makes it difficult for them to diffuse deeper into the adsorbent structure at high energy sites, therefore reduces adsorption. The decrease in adsorption can also be attributed to the fact that the pores are almost filled up. Resistance to diffusion of aggregated aspirin, ibuprofen and paracetamol molecules into activated carbon starts to increase and thereby reduce the rate at which adsorption occurs.

The graphs showing the effect of contact time for the three drugs approximates a plateau, which is an indication of saturation of activated carbon. The equilibration time for paracetamol, aspirin and ibuprofen was 75, 90 and 135 minutes respectively. This can be due to the difference in molecular size of the three drugs which increases in the order paracetamol, aspirin and ibuprofen. Pharmaceuticals with higher molecular masses, like ibuprofen, diffuse slower into the pores of the activated carbon, unlike smaller solutes like paracetamol and aspirin.

Effect of adsorbent dose on adsorption of aspirin, ibuprofen and paracetamol: Adsorbent dose is an important parameter in batch equilibrium studies. It determines sorbent-sorbate equilibrium of the system as well as the adsorption capacity of the adsorbent. The effect of activated carbon dose was studied using masses ranging from $0.5 \mathrm{~g}$ to $2.0 \mathrm{~g}$. Different amounts of activated carbon showed varying degree of adsorption for paracetamol, aspirin and ibuprofen. As shown in Figure 6, there is a direct relationship between mass of adsorbent and adsorption of aspirin, ibuprofen and paracetamol, that is, as the mass of activated carbon increases so does the removal rate of the drug. This can be attributed to the increase in the number of adsorption sites as a result of the increase in surface area as mass of adsorbent increases. At higher adsorbent doses, the rate of increase in adsorption slows down for all the drugs under study. This can be due to the partial aggregation or overlapping of the activated carbon which results in a decrease in effective surface area for the adsorbent [18]

Effect of $\mathrm{pH}$ on adsorption of aspirin, ibuprofen and paracetamol: The $\mathrm{pH}$ of the solution affects the surface charge of the adsorbent [35]. It also affects the degree of ionization of pharmaceuticals. At $\mathrm{pH}$ values around $\mathrm{pKa}$ (dissociation constant) values, aspirin, ibuprofen and paracetamol exist predominantly as neutral species. The nature of the solid surface, either hydrophobic or hydrophilic, and electrical interactions play an important role in adsorption kinetics [33]. Adsorption of pharmaceuticals occurs primarily in their unionized form. Figure 7 shows the effect of $\mathrm{pH}$ on adsorption of the pharmaceuticals under study.

Adsorption of aspirin was found to be high in the acidic range. Increase in $\mathrm{pH}$ in the acidic range results in increase in adsorption from $\mathrm{pH} 2.11$ to 3.97 and then 6.18. In alkaline conditions, increase in $\mathrm{pH}$ results in decrease in adsorption. Structural stability of aspirin is affected by $\mathrm{pH}$ changes.

As shown in the adsorption of aspirin, ibuprofen behaves in as much the same way. The neutral molecule of ibuprofen is the main structure between $\mathrm{pH} 2$ and 4. Adsorption increases from $\mathrm{pH} 1.98$ to 3.96 and then begins to fall in the alkaline range.

Maximum adsorption was found around $\mathrm{pH}$ 4. At this point, ibuprofen is not deprotonated. Its charge remains almost neutral and this could be the reason why more ibuprofen was adsorbed around $\mathrm{pH}$ 4. The $\mathrm{pKa}$ value of ibuprofen is around $\mathrm{pH} 4.5$. At $\mathrm{pH}$ values above its $\mathrm{pKa}$, it starts to deprotonate and develop a charge. There is lesser amount of neutral ibuprofen at $\mathrm{pH}$ above 4 as the anionic form of

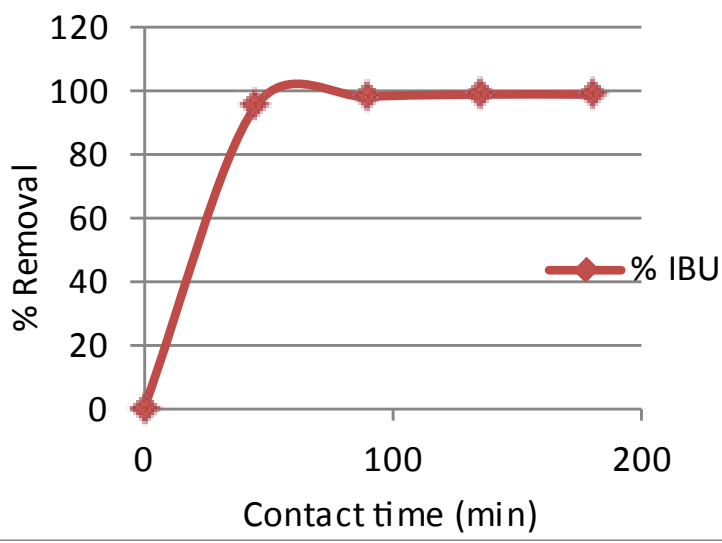

Figure 5: Effect of contact time on adsorption of ibuprofen.

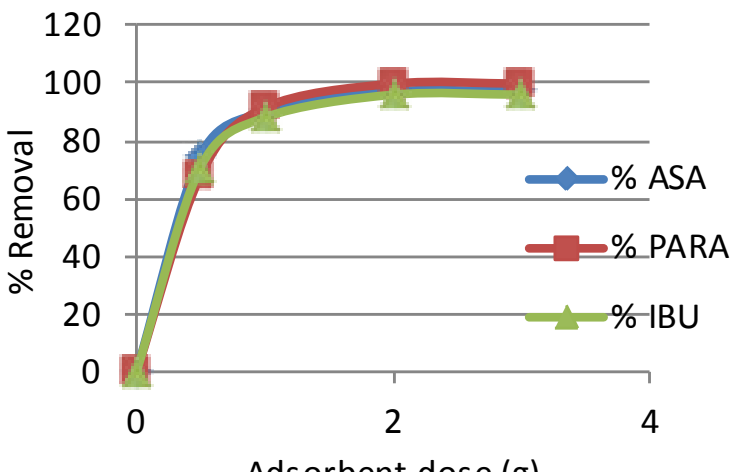

Figure 6: Effect of adsorbent dose on adsorption of aspirin, paracetamol and ibuprofen.

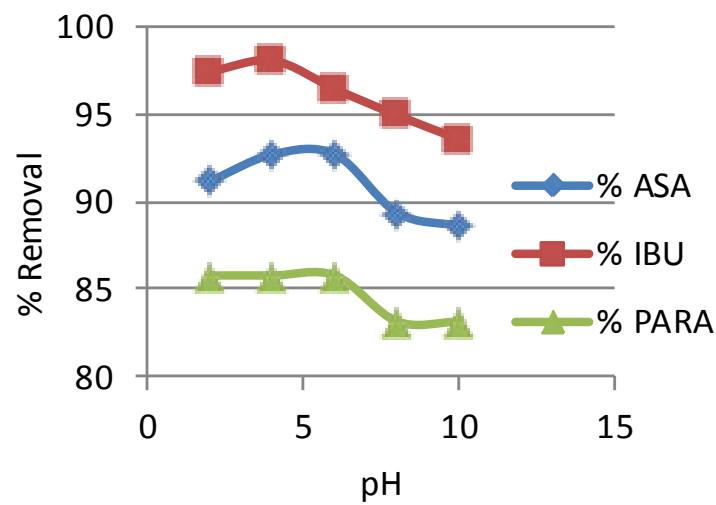

Figure 7: Effect of $\mathrm{pH}$ on adsorption of aspirin, paracetamol and ibuprofen.

ibuprofen starts to increase. The increase in anionic form results in decreased adsorption as the amount of neutral ibuprofen also decreases. High adsorption rates of ibuprofen at acidic $\mathrm{pH}$ are related to the lower solubility of the molecular form of ibuprofen at lower $\mathrm{pH}$ [36]. Lower solubility promotes its adsorption on activated carbon.

The decrease in adsorption at higher $\mathrm{pH}$ values can also be attributed to the weaker interactions of the deprotonated form of ibuprofen which will be dominant in solution with the surface of the activated carbon. 
This is in agreement with previous study on adsorption of ibuprofen [37] in aqueous solution. Negative charges on the graphitic layers repel this anionic form of ibuprofen and this repulsion results in reduced adsorption of ibuprofen.

Under acidic conditions, acidic groups are protonated and the carbon is either neutral or positively charged whereas ibuprofen is in neutral form. Adsorption under such conditions is enhanced as a result of reduced repulsive electrostatic interactions or by dominant dispersive interactions [38].

The effect of $\mathrm{pH}$ on adsorption of paracetamol was studied between $\mathrm{pH}$ values 2.10 and 10.22 . Between $\mathrm{pH} 2$ and 10, the majority of paracetamol molecules are present in their neutral form. The unionized form of paracetamol is slightly higher at lower $\mathrm{pH}$ values than above 8 .

The amounts adsorbed at $\mathrm{pH}$ values 2.10, 4.22 and 5.91 are expected to be slightly above those adsorbed at $\mathrm{pH} 8.10$ and 10.22 but there is no significant difference in adsorption between $\mathrm{pH} 2.10$ and 10.22 . There is slight change from $85.789 \%$ at lower $\mathrm{pH}$ (2.10) to $83.158 \%$ at higher $\mathrm{pH}$ (10.22). This indicates that adsorption of paracetamol is not greatly affected by $\mathrm{pH}$ changes from 2.10 to 10.22 .

Effect of initial concentration on adsorption of aspirin, ibuprofen and paracetamol: The initial concentration provides the driving force to overcome the resistances to the mass transfer of adsorbate between the aqueous and solid phases [39]. It also enhances the adsorbateadsorbent interactions. Figure 8 shows the effect of initial concentration on adsorption of aspirin, paracetamol and ibuprofen. Adsorption of aspirin decreased with increase in initial concentration from 20 to 80 $\mathrm{mg} / \mathrm{L}$. Saturation of the adsorption sites at higher initial concentrations of aspirin contributes to decreased adsorption. However, adsorption of aspirin was still high above $80 \%$ at higher initial concentrations (60 and $80 \mathrm{mg} / \mathrm{L}$ ).

As with aspirin, higher adsorption at lower paracetamol and ibuprofen concentrations can be due to the availability of more sites on the activated carbon than the solute molecules in solution. The lower adsorption percentages at higher concentration levels for all the three drugs have been observed as shown in Figure 8. This is because at higher concentration levels, the number of solute (pharmaceutical) molecules is relatively higher than the number of sites available for adsorption.

Effect of co-adsorption on removal of aspirin, paracetamol and ibuprofen: Adsorption of aspirin, paracetamol and ibuprofen depends on the molecular size of the drug, that is, the smaller solute diffuses faster into the pores of the activated carbon than larger ones. Paracetamol, being a smaller molecule, had higher removal rates with ibuprofen having the lowest rates because of its large size. Adsorption onto activated carbon showed lower adsorption capacity for aspirin, paracetamol and ibuprofen. This can be attributed to competitive adsorption among the three drugs.

\section{Adsorption isotherms}

The Langmuir model showed best fit for ibuprofen and paracetamol adsorption onto activated carbon as shown by the high correlation coefficients $\left(\mathrm{R}^{2}\right)$, which are 0.9995 and 0.9997 for ibuprofen and paracetamol respectively. This confirms monolayer adsorption of ibuprofen and paracetamol onto activated carbon. Previous studies $[38,40]$ reported similar observations (Figures 10 and 11 ).

The Freundlich model showed best fit for aspirin adsorption

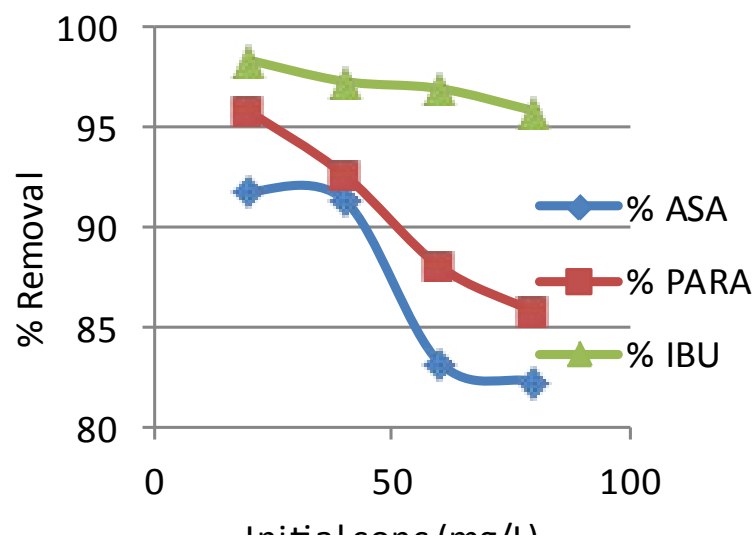

Figure 8: Effect of initial drug concentration on adsorption of aspirin, paracetamol and ibuprofen.

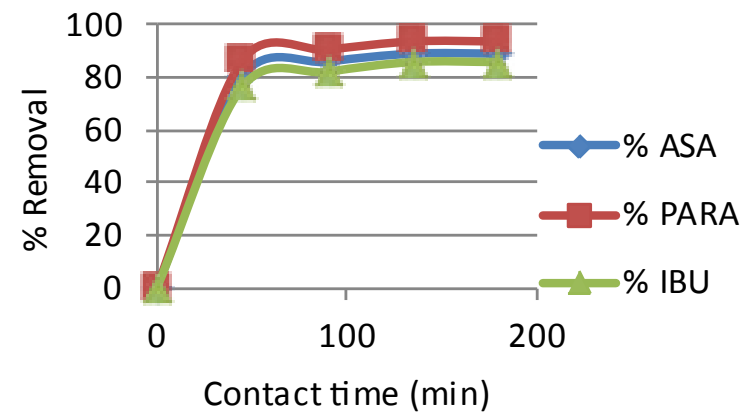

Figure 9: Effect of co-adsorption on removal of aspirin, paracetamol and ibuprofen.

onto rice hull activated carbon as shown by the $\mathrm{R}^{2}$ value of 0.9943 compared to 0.824 for the Langmuir model. However, the Langmuir model was far much better than the Freundlich model for ibuprofen and paracetamol adsorption as their $\mathrm{R}^{2}$ values were 0.9899 and 0.9811 , which are lower than those obtained for Langmuir model (0.9995 and 0.9997 respectively). Maximum monolayer adsorption capacities of aspirin, paracetamol and ibuprofen were found to be 178.89, 169.49 and $100 \mathrm{mg} / \mathrm{L}$ respectively (Table 1 ).

The intensity of adsorption is indicated by $\mathrm{n}$. The values of $\mathrm{n}$ for aspirin, paracetamol and ibuprofen are all lower than 10 as indicated in the Table 1. This indicates that the adsorption process for these drugs was favorable as values of $\mathrm{n}$ greater than unity indicate favorable adsorption conditions which are sui for highly heterogeneous surfaces indicating that adsorption process can still be described using Freundlich model even though the $\mathrm{R}^{2}$ values are lower for ibuprofen and paracetamol for the Freundlich model compared to those of the Langmuir. The $\mathrm{n}$ values of ibuprofen, aspirin and paracetamol (1.89, 1.84 and 2.27 respectively) prove that the adsorption process could be physical in nature $[41,42]$ highlighted that values of $\mathrm{n}$ in the Freundlich model between 2 and 10 indicate good adsorption.

The separation factor, $\mathrm{R}_{\mathrm{L}}$ shows the nature of adsorption mechanism. The $R_{L}$ values for aspirin, ibuprofen and paracetamol are within the range $0<R_{L}<1$. This means the nature of adsorption mechanism onto rice hull derived activated carbon was favorable for all the drugs. 


\section{Adsorption kinetics}

Kinetic studies were carried out to optimize different operating conditions for the adsorption of ibuprofen, aspirin and paracetamol. Rate of drug adsorption on rice hull activated carbon was studied by measuring change in concentration as a function of time. The volume, mass of adsorbent and initial concentration were kept constant.

Pseudo-first order, pseudo-second order and intraparticle diffusion kinetic models shown in equations 3-5 were used to evaluate experimental data and the results are shown in Table 2. Results in Table 2 indicate that the adsorption of ibuprofen, aspirin and paracetamol follows pseudo-second order equation. The $\mathrm{R}^{2}$ value which is equal to 1 for ibuprofen, 0.9995 for aspirin and 0.9973 for paracetamol indicates that the coefficient of determination is favorable and the model can adjust to the experimental data [43]. The $\mathrm{R}^{2}$ values indicate that adsorption of the drugs was not consistent with pseudo-first-order model as its values were lower than those obtained for pseudo-second order kinetics. Similar observation was reported [38] in his research on adsorption of ibuprofen from aqueous solution using activated carbon (Figures 12 and 13).

Plots of $\frac{t}{q t}$ against time (t) Figures 12 and 13 showed that an increase in contact time $(t)$ results in an increase in adsorption capacity. This proves that contact time, together with initial drug concentration and adsorbent dose are important parameters for the determination of the adsorption capacity of drugs onto activated carbon.

Intraparticle diffusion model also demonstrated high $\mathrm{R}^{2}$ values of $0.9256,0.9349$ and 0.8328 for aspirin, paracetamol and ibuprofen respectively. This indicates that pore diffusion also affects the rate of drug adsorption.

However, the intercepts of the plots do not pass through the origin. This indicates that intraparticle diffusion is not the only rate limiting step, but also other kinetic models may control the rate of adsorption [18]. The rate limiting step maybe a complex combination of chemisorption and intraparticle transport [44] (Table 2).

\section{Analysis of hospital wastewater samples}

After extraction procedure, the extract was analyzed using UV Vis spectrophotometer Genesys 10S UV VIS spectrophotometer supplied by Thermo Scientific. A number of peaks were observed when the wavelength was scanned from 200 to $400 \mathrm{~nm}$ as shown in Figure 14 . Peaks of interest were observed at 225, 243 and $278 \mathrm{~nm}$ for ibuprofen, paracetamol and aspirin respectively.

On addition of $1 \mathrm{~cm}^{3}$ each of $0.1 \%(\mathrm{w} / \mathrm{v})$ ferric chloride, $0.065 \%$ (w/v) potassium ferricyanide and $2 \mathrm{M}$ acetic acid to the extract, a blue solution was formed. When the derivatized blue solution was scanned between 400 and $800 \mathrm{~nm}$, major peak was observed around $732 \mathrm{~nm}$. The peak can be attributed to paracetamol. This wavelength value is the same as the maximum wavelength of $732 \mathrm{~nm}$ obtained when scanning a $200 \mathrm{mg} / \mathrm{L}$ paracetamol standard solution between 600 and $800 \mathrm{~nm}$ (Figure 15).

On derivatizing the extract using the aspirin derivatization procedure, a purple solution was formed. When this solution was scanned between 200 and $400 \mathrm{~nm}$, the peak around $278 \mathrm{~nm}$ did not appear. This suggests that it might have shifted away from this range. However, when scanned between 500 and $700 \mathrm{~nm}$, a significant peak was observed around $537 \mathrm{~nm}$ as shown in Figure 15. This can be due to aspirin as scanning of the $200 \mathrm{mg} / \mathrm{L}$ aspirin standard gave maximum wavelength of $538 \mathrm{~nm}$ (Tables 4 and 5).
Aspirin concentration averaged $0.15 \mathrm{mg} / \mathrm{L}$, whilst paracetamol ranged between 0.11 to $0.12 \mathrm{mg} / \mathrm{L}$. Ibuprofen ranged between 0.010 to $0.012 \mathrm{mg} / \mathrm{L}$. Previous studies $[3,45]$ indicate that these pharmaceuticals are present in hospital wastewater and the concentrations may be higher than $100 \mu \mathrm{g} / \mathrm{L}$.

Hospital wastewater contained lower concentrations of drugs compared to quantities that are consumed by patients at the hospital. This can be due to degradation or transformations the drugs undergo in the human body. This transformation results in release of significant amounts of metabolites into the aquatic environment. More than 90\% ibuprofen is transformed into hydroxyl and carboxyl derivatives and their metabolites are most likely to be high considering the transformation rate of more than $90 \%$ for ibuprofen [46].

Adsorption using activated carbon proved successful in the removal of aspirin, paracetamol and ibuprofen in hospital wastewater. This can be attributed to the lower concentrations of the drugs in the wastewater as it was proved during batch equilibrium studies that adsorption is high at lower initial concentrations because the number of pharmaceutical waste particles is relatively lower compared to the number of sites available for adsorption.

\section{Conclusion}

Activated carbon prepared from Zimbabwean rice hull, an agriculture waste is capable of removing ibuprofen, aspirin and paracetamol from aqueous solutions and hospital effluent.

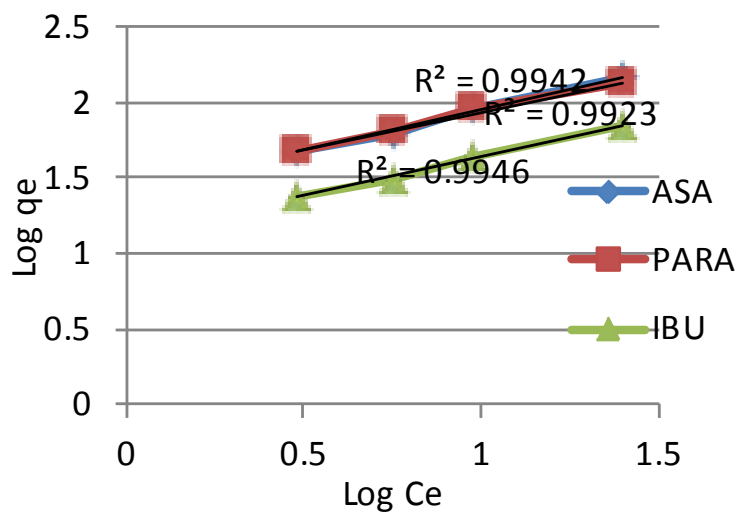

Figure 10: Freundlich adsorption isotherms for aspirin, paracetamol and ibuprofen.

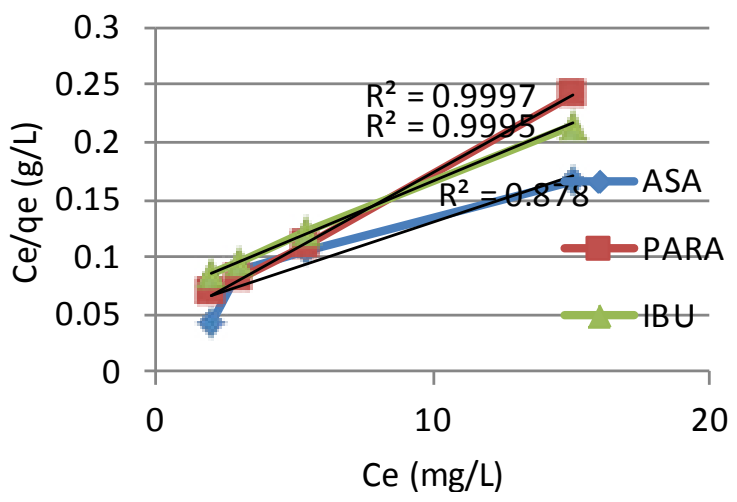

Figure 11: Langmuir adsorption isotherm for aspirin, paracetamol and ibuprofen. 


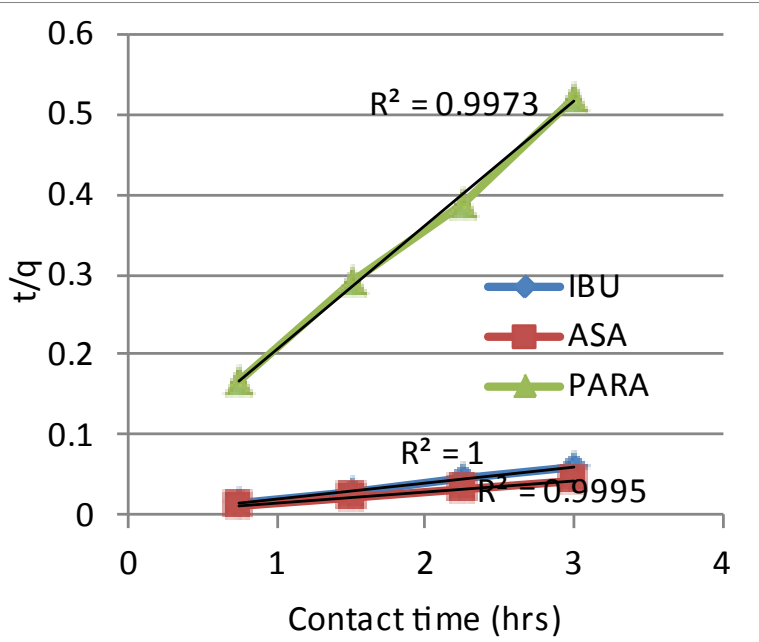

Figure 12: Plot of adsorption capacity versus time for aspirin, paracetamol and ibuprofen.

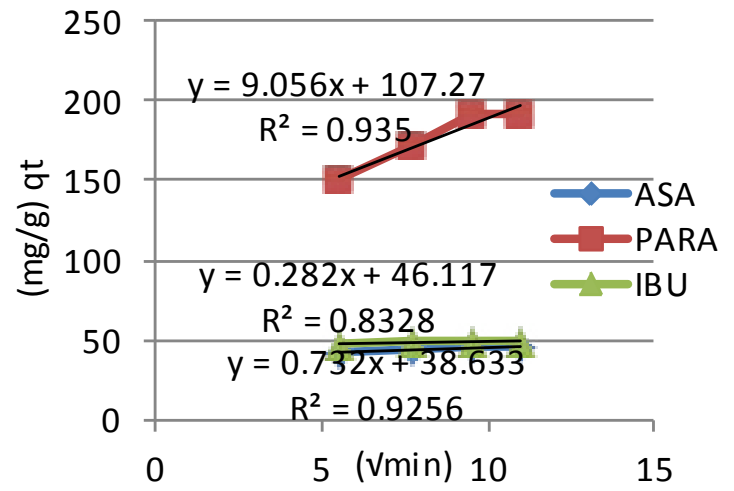

Figure 13: Intraparticle diffusion study of aspirin, paracetamol and ibuprofen adsorption.

\section{A}

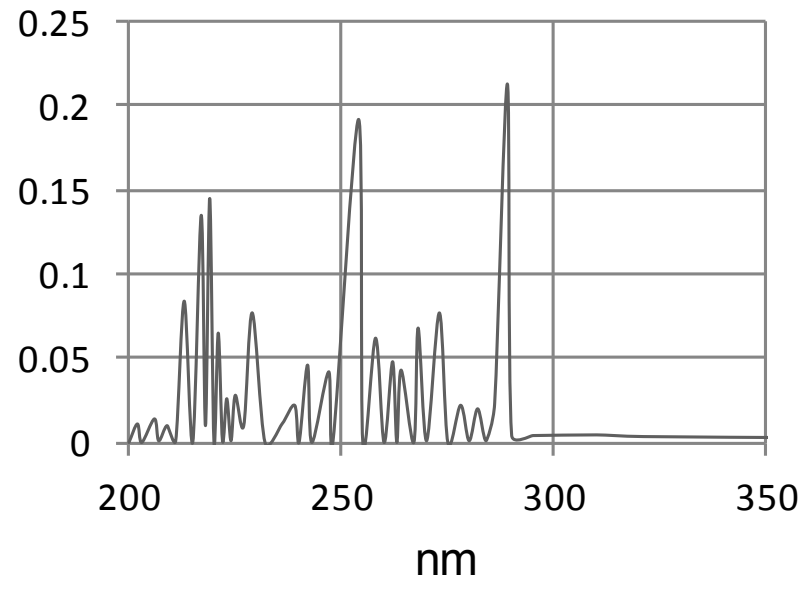

Figure 14: UV spectrum for mission hospital effluent.

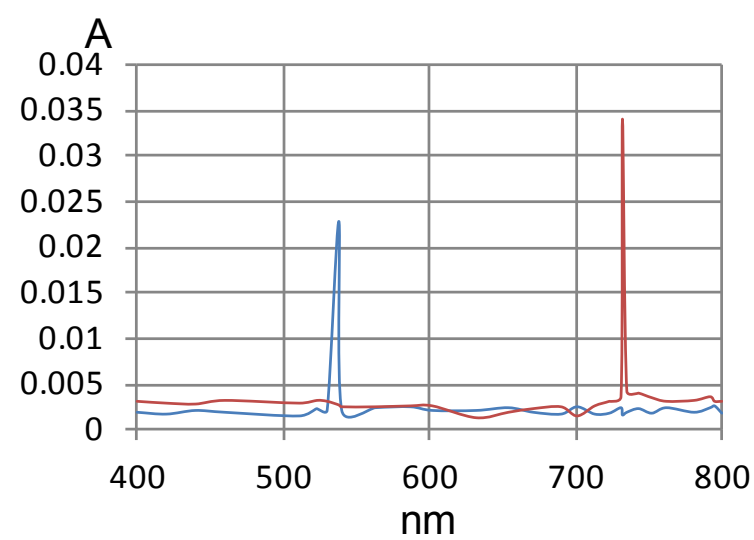

Figure 15: UV spectra for derivatized aspirin and paracetamol.

\begin{tabular}{|c|c|c|c|}
\hline Drug & Sample 1 & Sample 2 & Sample 3 \\
\hline Aspirin & 0.120 & 0.110 & 0.120 \\
\hline Paracetamol & 0.100 & 0.100 & 0.100 \\
\hline Ibuprofen & 0.010 & 0.011 & 0.010 \\
\hline
\end{tabular}

Table 4: Results of wastewater analysis before adsorption - Hospital 1.

\begin{tabular}{|c|c|c|c|}
\hline Drug & Sample 1 & Sample 2 & Sample 3 \\
\hline Aspirin & 0.00 & 0.00 & 0.00 \\
\hline Paracetamol & 0.00 & 0.00 & 0.00 \\
\hline Ibuprofen & 0.00 & 0.00 & 0.00 \\
\hline
\end{tabular}

Table 5: Results of wastewater analysis after adsorption - Hospital 1.

The activated carbon was characterized using FT-IR, SEM and XRD. FT-IR spectrum showed the presence of $-\mathrm{OH}, \mathrm{C}=\mathrm{C}, \mathrm{C}=\mathrm{O}$ and aromatic $\mathrm{C}-\mathrm{H}$ groups. SEM micrograph of activated carbon showed the external surfaces of the adsorbent have lot of regular cavities, with large pore sizes (mesoporous). XRD pattern showed broad peak indicating that the rice hull activated carbon produced has an amorphous structure.

The experimental data for adsorption of aspirin onto rice hull derived activated carbon fitted well to the Freundlich model, whereas adsorption of ibuprofen and paracetamol fitted to the Langmuir. Adsorption of the three drugs onto activated carbon showed best fit to the pseudo - second order kinetic model. Langmuir maximum adsorption capacities of $169.49,100.00$ and $178.89 \mathrm{mg} / \mathrm{g}$ were obtained for paracetamol, ibuprofen and aspirin.

The results from the study reveal that the removal of the studied pharmaceutical wastes increases with the increase in adsorbent dose, contact time and decreasing initial concentration whereas $\mathrm{pH}$ affects the structural stability of the pharmaceuticals. Adsorption of aspirin and ibuprofen was found to be in the maximum in the acidic region $(\mathrm{pH}=4)$ whereas paracetamol was not affected mainly by $\mathrm{pH}$ changes in the $\mathrm{pH}$ region of 2 to 10 .

Results show that ibuprofen, aspirin and paracetamol are present in hospital wastewater and studying the occurrence of pharmaceuticals is important in order to understand the contribution of hospital wastewaters to wastewater treatment plants and finally the environment.

Aspirin, paracetamol and ibuprofen were found in wastewater from the Mission hospital under study. This indicates that degradation or transformation in the human body does not completely remove these drugs. Derivatization for the purpose of adding strong UV chromophore in the analysis of pharmaceuticals is encouraged if wastewater is to be analyzed. 
Citation: Mukoko T, Mupa M, Guyo U, Dziike F (2015) Preparation of Rice Hull Activated Carbon for the Removal of Selected Pharmaceutical Waste Compounds in Hospital Effluent. J Environ Anal Toxicol S7: 008. doi:10.4172/2161-0525.S7-008

\section{Acknowledgement}

The authors sincerely thank Cape Town University for their help in the analysis (SEM and XRD) of activated carbon.

\section{References}

1. Moll DM, Frick EA, Henderson AK (1999) Presence of pharmaceuticals in treated wastewater effluent and Surface water supply systems, Metropolitan Atlanta, Georgia.

2. WHO, 20, Pharmaceuticals in drinking water, WHO/HSE/WSH/11.05, WHO Press, Geneva.

3. Kümmerer K (2009) The presence of pharmaceuticals in the environment due to human use--present knowledge and future challenges. J Environ Manage 90: $2354-2366$

4. Daughton CG, Ternes TA (1999) Pharmaceuticals and personal care products in the environment: agents of subtle change? Environ Health Perspect 107 Suppl 6: 907-938.

5. Kümmerer K (2001) Drugs in the environment: emission of drugs, diagnostic aids and disinfectants into wastewater by hospitals in relation to other sources-a review. Chemosphere 45: 957-969.

6. Boxall A, Roger B (2003) Pharmaceuticals and Personal Care Products in the Environment: Regulatory Drivers and Research Needs. QSAR and Combinational Science 22: 399-409.

7. Bartelt-Hunt SL, Snow DD, Damon T, Shockley J, Hoagland K (2009) The occurrence of illicit and therapeutic pharmaceuticals in wastewater effluent and surface waters in Nebraska. Environ Pollut 157: 786-791.

8. Carrara C, Ptacek CJ, Robertson WD, Blowes DW, Moncur MC, et al. (2008) Fate of pharmaceutical and trace organic compounds in three septic system plumes, Ontario, Canada. Environ Sci Technol 42: 2805-2811.

9. Baccar R, Sarrà M, Bouzid J, Feki M, Blánquez P (2012) Removal of pharmaceutical compounds by activated carbon prepared from agricultural byproduct. Journal of Chemical Engineering 211-212: 310-317.

10. Mohd Din AT, Hameed BH, Ahmad AL (2009) Batch adsorption of phenol onto physiochemical-activated coconut shell. J Hazard Mater 161: 1522-1529.

11. Roth M (2003) Pharmaceuticals in the environment', Retrieved from Campus Ecology (WSU).

12. Wright - Walters M, Voltz C (2009) Municipal wastewater concentrations of pharmaceutical and xenoestrogens: Wildlife and human health implications. Environmental Science and Technology $103-113$.

13. Körner W, Hanf V, Schuller W, Kempter C, Metzger J, et al. (1999) Development of a sensitive E-screen assay for quantitative analysis of estrogenic activity in municipal sewage plant effluents. Sci Total Environ 225: 33-48.

14. Isoda N, Rodrigues R, Silva A, Gonçalves M, Mandelli D, et al. (2014) Optimization of preparation conditions of activated carbon from agriculture waste utilizing factorial design. Powder Technology 256: 175-181.

15. Hameed BH, Tan IAW, Ahmad AL (2008) Adsorption isotherm, kinetic modeling and mechanism of 2,4,6-trichlorophenol on coconut husk-based activated carbon. Chemical Engineering Journal 144: 235-244.

16. Ahamed KR, Chandrasekaran T, Kuma AA (2013) Characterization of activated carbon prepared from Albizia lebbeck by physical activation. International Journal of Interdisciplinary Research and Innovation 1: 26-31.

17. Soto ML, Moure A, Dominguez H, Parajo JC (2011) Recovery, concentration and purification of phenolic compounds by adsorption: A review. Journal of Food Engineering 105: 1-27.

18. Kilic M, Apaydin-Varol E, Putun AE (2011) Adsorptive removal of phenol from aqueous solutions on activated carbon prepared from tobacco residues: Equilibrium, kinetics and thermodynamics. Journal of Hazardous Materials 189: 397-403.

19. Soleimani M, Kaghazchi T (2014) Low cost adsorbents from agricultural byproducts impregnated with phosphoric acid. Advanced Chemical Engineering Research 3: 34-41.

20. Zhang Y, Ghaly AE, Li B (2012) Physical properties of rice residues as affected by a variety and climatic and cultivation conditions in three continents. American journal of Applied sciences 9: 1757-1768.
21. Otaru AJ, Ameh CU, Abdulkareem AS, Odigure JO, Okafor JO (2013) Development and characterization of adsorbent from rice husk to bleach vegetable oils. Journal of Applied Chemistry 4: 42-49.

22. Kalderis D, Bethanis S, Paraskeva P, Diamadopoulos E (2008) Production of activated carbon from bagasse and rice husk by a single-stage chemical activation method at low retention times. Bioresour Technol 99: 6809-6816.

23. Suguraman P, Priya SV, Ravichandran P, Seshadiris S (2012) Production and characterization of activated carbon from banana empty fruit bunch and Delonix regia fruit pod. Journal of sustainable energy and environment 3: 125-132.

24. Birbas D (20) Preparation of activated carbon: Forest residues activated carbon with phosphoric acid \& zinc sulfate. MSc thesis, Royal Institute of Technology, Sweden.

25. Al-Okab RA, Syed A (2012) New and highly sensitive spectrophotmetric method for the determination of paracetamol in preformulation and dosage forms. International Journal of Analytical and Bioanalytical Chemistry 4: 209213.

26. Engelhart DA, Jenkins AJ (2007) Comparison of drug concentrations in postmortem cerebrospinal fluid and blood specimens. J Anal Toxicol 31: 581587.

27. Hassan AF, Mortada WI, Hassanien MM (2013) Preparation and characterization of activated carbon based rice husk and its use for pre-concentration of $\mathrm{Pt}(\mathrm{II})$ International Journal of Modern Chemistry 5: 101-117.

28. Akhtar M, Iqbal S, Kausar A, Bhanger MI, Shaheen MA (2010) An Economically Viable Method for the Removal of Selected Divalent Metal Ions from Aqueous Solutions Using Activated Rice Husk. Colloids and Surfaces B: Biointerfaces 75: $149-155$

29. Garg VK, Bansal M, Garg U, Singh D (2009) Removal of Cr(VI) from aqueous solutions using pre-consumer processing agricultural waste: A case study of rice husk. Journal of Hazardous Materials 162: 312-320.

30. Salame I, Bandosz TJ (2000) Effect of surface chemistry and pore structure on adsorption of water and methanol on activated carbons. Do, D. (ed.), Second Conference on Adsorption Science and Technology, World Scientific, Hong Kong, $61-65$.

31. Chuah TG, Jumasiah A, Azni I, Katayon S, Chong SYT (2005) Rice husk as a potentially low-cost biosorbent for heavy metal and dye removal: an overview. Desalination 175: 305-316.

32. Zhu X, Wang P, Peng C, Yang Y, Yan X (2014) Activated carbon produced from paulownia sawdust for high-performance $\mathrm{CO}_{2}$ sorbents. Chinese Chemical Letters 25: 929-932.

33. Vergili I, Barlas H (2009) Removal of selected pharmaceutical compounds from water by an organic polymer resin. Journal of Scientific and Industrial Research 68: $417-425$.

34. Adak A, Bandyopadhyay M, Pal M (2005) Removal of anionic surfactant from wastewater from alumina: A case study. Colloid Surface A 254: 165-171.

35. Srivastava VC, Swamy MM, Mall ID, Prasad B, Mishra IM (2006) Adsorptive removal of phenol by bagasse fly ash and activated carbon: equilibrium, kinetics and thermodynamics. Colloids Surf. A: Physicochemical Engineering Aspects 272: 89-104.

36. Shaw LR, Irwin WJ, Grattan TJ, Conway BR (2005) The effect of selected water-soluble excipients on the dissolution of paracetamol and Ibuprofen. Drug Dev Ind Pharm 31: 515-525.

37. Mestre AS, Pires J, Nogueira JMF, Carvalho AP, Ania CO (2009) Wastederived activated carbons for removal of ibuprofen from solution: role of surface chemistry and pore structure. Bioresour Technol 100: 720-1726.

38. Guedidi H, Reinert L, Lévêque JM, Soneda Y, Bellakhal N, et al. (2013) The effect of the surface oxidation of activated carbon, the solution $\mathrm{pH}$ and the temperature on adsorption of ibuprofen. Carbon 54: 432 - 443.

39. Pakhre V, Srivastava VC (2012) Adsorption of Benzoic acid and Salicylic acid onto granular activated carbon. International conference on Chemical, civil and Environmental engineering, Dubai, March 24 - 25, 261-265.

40. Connors S (2013) Removal of ibuprofen from drinking water using adsorption. Thesis, Worcester Polytechnic institute. 
Citation: Mukoko T, Mupa M, Guyo U, Dziike F (2015) Preparation of Rice Hull Activated Carbon for the Removal of Selected Pharmaceutical Waste Compounds in Hospital Effluent. J Environ Anal Toxicol S7: 008. doi:10.4172/2161-0525.S7-008

41. Behnamfard A, Salarirad MM (2009) Equilibrium and kinetic studies on free cyanide adsorption from aqueous solution by activated carbon. $\mathrm{J}$ Hazard Mater 170: 127-133.

42. Erdem E, Cölgeçen G, Donat $R$ (2005) The removal of textile dyes by diatomite earth. J Colloid Interface Sci 282: 314-319.

43. Mestre AS, Pires J, Nogueira JMF, Carvalho AP (2007) Activated carbons for the adsorption of ibuprofen. Carbon 45: 1979-1988
44. Luna MD, Flores FD, Genuino DAD, Futalan CM, Wan MW (2013) Adsorption of Eriochrome Black T dye using activated carbon prepared from waste rice hulls - Optimization, isotherm \& kinetic studies. Journal of the Taiwan Institute of Chemical Engineers 44: 646-653.

45. Hartmann A, Golet EM, Gartiser S, Alder AC, Kollers T, et al. (1999) Primary DNA damage but not mutagenicity correlates with ciprofloxacin concentrations in German hospital wastewaters. Archiv Environ Contam Toxicol 36: 115 -119.

46. Khamis M, Karaman R, Ayyash F, Qtait A, Deeb O, et al. (2011) Efficiency of advanced membrane wastewater treatment plant towards removal of aspirin, salicylic acid, paracetamol \& p- aminophenol. Journal of Environmental Science \& Engineering 5: 121-137. 